\title{
TIBF DAY-OF-THE-WEEK EFFECT AND VOLATILITY IN STOCK RETURNS: EVIDENCE FROM EAST ASIAN FINANCIAL MARKETS
}

\author{
Chiaku Chukwuogor-Ndu \\ Eastern Connecticut State University, United States \\ of America
}

\begin{abstract}
The presence of the day-of-the-week effect has been documented in finance literature. This paper investigates the presence of the day-of-the-week effect and return volatility in ten East-Asian financial markets in the post Asian financial crisis period, after 1998. A set of parametric and non-parametric tests is used to test the equality of mean returns and standard deviations of returns. The results indicate the presence of the day-of-the-week effect and insignificant daily returns volatility in most markets. Some of these results reinforce some previously documented evidence and others are at variance with published results for the same markets. This effect, unlike in devloped markets, is still persistent.
\end{abstract}

JEL Classification: G14 \& G15

Key words: returns, volatility, standard deviation, anomalies, day-of-the-week effect, kurtosis, skewness.

\section{Introduction and anomaly literature}

The objective of this paper is to examine the day-of-the-week stock return patterns and determine the volatility of returns of ten East Asian stock markets to provide empirical evidence in the post-1997 Asian Financial crisis period. The presence of anomalies in returns of common stocks reported for developed markets has intrigued finance researchers since the 1980s. There is need to examine this phenomenon in Asia's emerging capital markets (especially after the crisis), since all countries in Asia have introduced pro-market reforms and strengthened the institutional structures of the market pricing processes. The results reported for most developed markets have led to further challenges to the appropriateness of the Efficient Market Hypotheses (EMH). 
The day-of-the-week effect in share returns in the US has been well documented. The mean return on Mondays is negative, and is significantly lower than the mean return on any other day of the week. The mean returns are significantly higher on Fridays relative to other days (see Fama (1965), Gibbons et al. (1981), Lakonishok et al. (1982), Keim et al. (1984), and Mehdian and Perry (2001)). Jaffee et al. (1985a; b) found a negative Monday effect in Canada and the U.K., but a negative Tuesday effect in Japan and Australia. Condoyanni et al. (1987) confirms these findings on the Japanese and Australian markets. Kato (1990) also found that the Tuesday return is negative and Wednesday and Saturday returns are strongly positive in Japan. Jaff et al. (1989) wrote a significant paper providing international evidence. Colorful phrases have crept into the literature. Bad-Friday effect, which refers to a decline of the market on Fridays, usually precedes Monday with increased stock selling pressure.

Turning now to Asian markets, the-day-of-the-week effect on stock has also been evidenced in several Asian stock markets before the Asian financial crisis, 1997. These markets were characterized as having very high returns, high volatility in returns, and high illiquidity. East Asian markets in the post-crisis years still remains of great interest because of high economic growth rates that lead to high market returns. Wong et al. (1986) reported evidence of day-of-the-week and seasonal effect in the Singapore market. The pattern was similar to that of the US market. One difference noted is that, in Japan and Australia, mean return is negative on Mondays and the highest positive return occurs on Fridays. The mean daily return in January is higher than that for other months, although the end-of-year effect is not significant at all. Aggarwal et al. (1989) noted day-of-the-week effect in Hong Kong, Korea, Taiwan, Japan, and Singapore, while Ho's (1990) paper finds strong, seasonality effect - an evidence against the EMH - in ten Asia-Pacific markets, further confirming the day-of-the-week effect in Singapore, Malaysia, Hong Kong, and Thailand. Chen, Kwok, and Rui (2001) reported dayof-the-week effect in China, showing negative Tuesdays after 1995 and highlighting that this anomaly disappears once non-normality and spill-over from other countries is taken into account.

The rest of the paper is organized into four more sections. The following section is an introduction to the ten markets, selected for this study. In Section 3 the reader may find a description of the data, variables, and the measurement methods. The results are presented in Section 4 and the paper is concluded as Section 5 .

\section{Overview of the markets included}

Most of the documented studies on the day-of-the week-effect on returns and returns volatility in EAFM were done before July 1997, the time of the Asian financial crisis. The choice of post-crisis period is appropriate for two important 
reasons. The crisis was perpetrated by the financial fragility of South Korean and Thai economies, which first led to the sudden collapse of their two currencies in the first two weeks of July 1997. Thereafter, the contagion of currency decline spread to other neighboring trading partner countries, resulting in both political and economic changes of far-reaching magnitude. The South Korean won depreciated by 88.40 percent, and the Thai baht depreciated by 64 percent. With that magnitude of currency collapses in the two and other countries, governments had to call the IMF for restructuring their economies with massive bailout loans. IMF initially approved US \$35 billion financial support for reform programs in Indonesia, South Korea, and Thailand. Later, the amount ballooned to US \$77 billion of additional financing (see IMF (1999)).

The gross domestic product growth rates of Asian countries dropped from very close to double-digit, to negative territory. Singapore, South Korea, Thailand, and Taiwan registered negative growth rates in 1998. After the recovery brought on through IMF bailout, reforms, and restructuring, several Asian countries achieved very high GDP growth rates (see Figure 1).

Figure 1:Economic Growth Rates in the Ten Selected Markets: 1990-2002

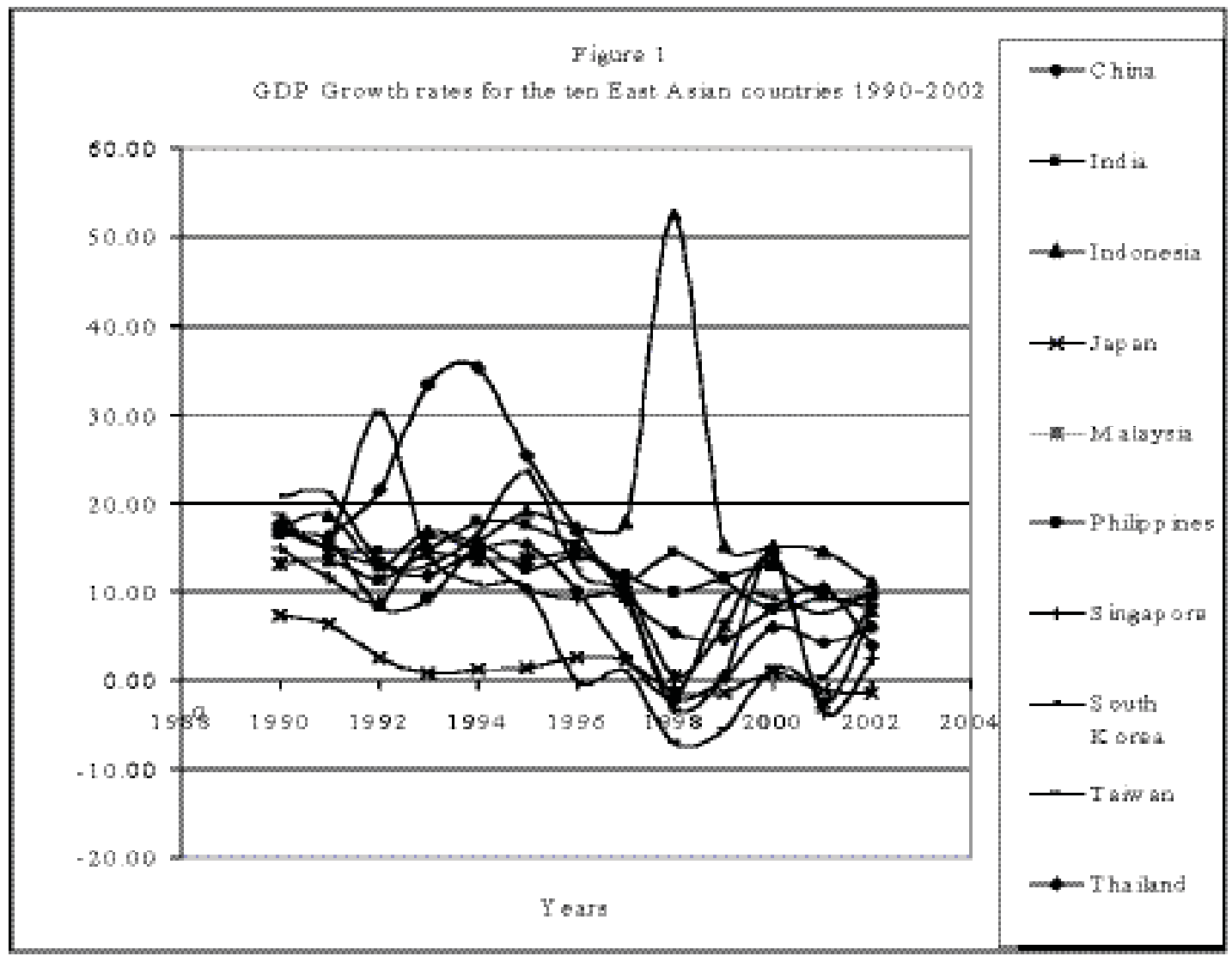

Source: This Figure is constructed from data from IMF International Financial Statistics, 2003, CD-Rom, at the University of Connecticut, U.S. as at June 2004. 
The post-crisis recovery phase is from 1999, whereas the charts show the pre-crisis growth rates as well. Except Taiwan, growth rates were around 9 or more percent per year in the years before 1996. But when the crisis occurred in 1998, growth rates declined suddenly to a region below the 10 percent level, and in three cases, below 0. Even though Figure 1 shows that Indonesia achieved a very high GDP growth rate in 1998, (probably due to the gross inflow of funds from multilateral and bilateral sources), the situation in all the other East Asian countries was generally very poor. In addition to the severe effects, the crisis put pressure on emerging markets outside the region contributing to a virulent contagion and volatility increases in international financial markets.

The impact was more pronounced on the Asian economies because of the traditional trade links that exists among them. Prior to the crisis, these financial markets were characterized as having yet completed prudential market regulation that would be required to secure stability. Following the severe impact of the crisis, and under the tutelage of the IMF, and other international bodies, necessary reforms were put in place, and these reforms not only improved the economic performance, but also contributed to the capital markets improved liquidity and prudential management. If that is true, it is a worthwhile effort to motivate this study to see if the post-crisis behavior is different from that documented for an earlier era.

\section{Data and methodology}

To do this, the daily closing prices of ten East Asian stock market indices were identified for scrutiny. Parametric and non-parametric tests were used to test the equality of mean returns across the-day-of-the-week and the equality of the standard deviations across the-day-of-the week. We use the daily closing values market indices from January 1998 to October 31, 2003. The period covered 5 years and ten months. The financial market indices included are:

- China's Shanghai Composite (SSEC)

- India's BSE 30 (BSESN)

- Indonesia's Jakarta Composite (JK)

- Japan's Nikkei 225 (N225)

- Malaysia’s KLSE Composite (KLSE)

- $\quad$ Philippines' PSE Composite (PSI)

- $\quad$ Singapore's Straits Times (STI)

- $\quad$ South Korea's Seoul Composite (KSII)

- Thailand's SET (SETI) for Thailand

- Taiwan's Taiwan Weighted (TWII) 
The daily stock returns for the East Asian stock indices are calculated as follows:

\section{Where}

$$
\ln \left(P / P_{t-1}\right) * 100
$$

$\boldsymbol{P}_{i}$ : the stock market index value at date $t$ and $t-1$.

The ratio multiplied by 100 gives the cent returns for each day for each market. Except for the returns on Monday we excluded any returns that are preceded by a holiday. This exclusion was done to avoid the speculation that observed day-of-the-week-effect could be partially due to these non-trading days. The returns are then calculated for each day of the week. A similar procedure is applied to compute the sample standard deviations of each day's observations in each market. We used the standard deviations in the returns to measure volatility. Then, we tested the hypothesis of equal variance as substantiated by non-parametric tests. To test the hypothesis of an equal mean return across all days of the week, we applied the non-parametric Kruskal-Wallis statistics:

$$
\frac{12}{N(N+1)} \sum_{N-1}^{\frac{1}{n_{j}}} \frac{R_{I}^{2}}{n_{j}}-3(w+1)
$$

Where:

$\mathbf{K}$ : the number of observations in each of the samples,

$\mathbf{n}_{\mathbf{j}}$ : the number of values in the $j^{\text {th }}$ sample,

$\mathbf{N}: \sum n_{j}=$ total number of values,

$\mathbf{R}_{\mathrm{j}}$ : the sum of ranks in the sample when $N$ values are ranked together.

This statistic is approximately Chi-square distributed with degrees of freedom equal to k-1. We employ the Levene's (1960) test to check the results on equality of variance. In measuring the variation within a class, Levene's test uses the average of the absolute deviations instead of the mean square of deviations. This avoidance of squaring makes the test criterion much less sensitive to nonnormal distributions (see Snedecor et al. (1976)):

Where

$$
F=\left[\sum_{j=1}^{J} n_{j}\left(D_{j}-D_{j}\right) j \sum_{-1}^{J} \sum_{t=1}^{\sum_{t}}\left(D_{v}-D_{v}\right)^{2}\right] x\left[\frac{(N-J)}{(J-1)}\right]
$$

with Rij is the return for week $i$ for the weekday $j$ for $j=1,2, \ldots$,

$\mathrm{J}=5$ if the last trading day of the week is a Friday (it is the case in all countries)

$\mathrm{M}=$ is the mean of the sample

$\mathrm{D}=$ denotes the difference being tested.

These tests are robust enough to yield reliable results on the comparisons of mean and standard deviations, without the results being biased due to the nonnormality of distributions. 


\section{Empirical results}

The results are grouped in two sub-sections. First to be presented are the results for the day-of-the-week mean returns in sub-section below.

\section{A. Day-of-the-Week Effect}

Table 1:Daily mean and standard deviations of returns of 10 markets, 1998-2003

\begin{tabular}{|c|c|c|c|c|c|c|}
\hline 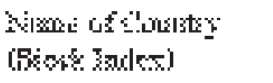 & Matkitar & गिलA & statsentar & Shaptast & Fide & 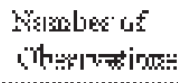 \\
\hline $\begin{array}{l}\text { बins } \\
{[\$ \% \%)}\end{array}$ & $-1,0189$ & $0,0) \Gamma$ & ants? & $-1,601$ & 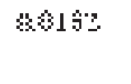 & $5 \%$ \\
\hline 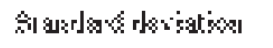 & \$:4 & $\leftrightarrow \otimes 1$ & $x \rightarrow$ & 6tes & $\$ 4 \%$ & \\
\hline 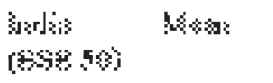 & 20,6 & 0.001 & 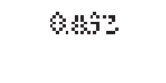 & $0.4 \%$ & $-(0,1) I 2$ & $\nabla: 13$ \\
\hline 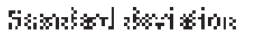 & $40 \times 13$ & $\leftrightarrow \oplus 1$ & $060 x$ & $\oplus .69 \%$ & 439 & \\
\hline 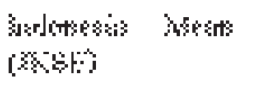 & -0.0is & $6 \% 3$ & $-40: 1$ & $0 \% s$ & $\Delta \leftrightarrow \bullet 1$ & 394 \\
\hline 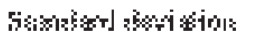 & s soss & 0.513 & ass: & $.3 \sin$ & $\Delta \% \%$ & \\
\hline 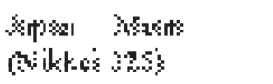 & - 0009 & $0,07<5$ & -40014 & -0.405 .4 & $-\$ \oplus 19$ & $5 T 28$ \\
\hline 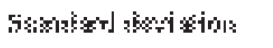 & $4: 4 \%$ & $42 \% 2$ & kn:1 & .696 & $.61: 3$ & \\
\hline 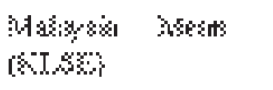 & - 1036 & $0.0 \% 1$ & $x \operatorname{list}$ & 0.013 & $\Delta \phi 31 \%$ & 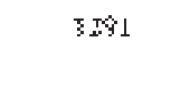 \\
\hline semater peratin: & 4956 & $3.0 \mathrm{~s} 1 \mathrm{~s}$ & 109 & $0.64 \%$ & $4 \div 41$ & \\
\hline $\begin{array}{l}\text { Wilopives Mrens } \\
\text { prom }\end{array}$ & $46: 5 \%$ & .6093 & - Los? & 0415 & $\Delta \oplus 19$ & 751 \\
\hline 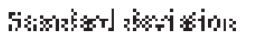 & $4 \uparrow \$ \perp$ & bx & $\leftrightarrow$ & $\Leftrightarrow 3$ &. $\min$ & \\
\hline 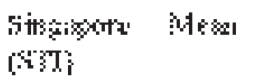 & - 1064) & $-(1,0) \%$ & 40104 & $6,1)$ & $A \leftrightarrow \leftrightarrow$ & 75 \\
\hline 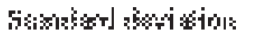 & 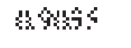 & 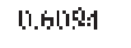 & 4? & Sin & 6045 & \\
\hline 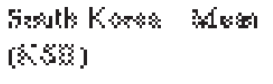 & $-\leftrightarrow \phi$ & 0 & $4 \pi 3$ & $-114 \%$ & 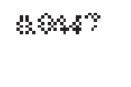 & TISI \\
\hline 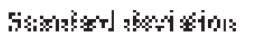 & $1.13 \%$ & 8.0051 & 1.2115 & 906 & $1 . \% 15$ & \\
\hline 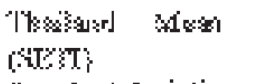 & $-0.26 \%$ & 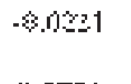 & $10 \leqslant 15$ & $0 \% 2 \perp$ & $41 \mathrm{~m}$ & $5 I 18$ \\
\hline 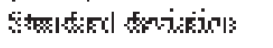 & $\infty \times m$ & i]. $7 x$ & 0907 & [..82\% & ब\$Bश & \\
\hline 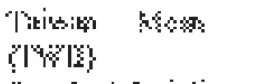 & $\leftrightarrow \leftrightarrow \top \mathrm{T}$ & $\sin \theta$ & 6.0 .90 & $11 \% 137$ & $\$ \$ 105$ & $3+\infty$ \\
\hline 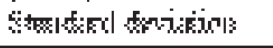 & 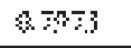 & $0.1 .907 \pi$ & 6795 & 0.785 & $45=6$ & \\
\hline
\end{tabular}

Table 1 provides a summary of statistics on the mean returns for each day of the week and the standard deviations across the days of the week for the ten East Asian financial markets. Similar to the US case and the case of results relating to the pre-Asian financial crisis Asian case, seven of the ten East Asian markets 
show negative mean Monday returns. The markets include China, Indonesia, Malaysia, Japan, Singapore, South Korea, and Thailand. The returns of Indonesia, Malaysia, and Thailand are marginally significant at the $10 \%$ acceptance level.

Philippines, Thailand, and Taiwan show negative Tuesday returns. In precrisis studies on day-of-the-week returns, Taiwan showed positive returns on Tuesday. Consistent with past results, the stock market returns of Philippines and Taiwan are significantly negative at the $10 \%$ acceptance level. Indonesia, Japan, and the Philippines show negative Wednesday returns. China, Japan, South Korea, and Taiwan show negative Thursday returns. In pre-crisis studies, Thursday returns in all Asian Financial markets were positive (see Ho (1990)).

All the East Asian stock markets except those in Japan and India have positive Friday returns. But only a few were significantly positive: South Korea and Thailand at 10\% acceptance level and Malaysia at 5\% acceptance level.

Table 2 summarizes the days in which the highest and lowest return or standard deviations occur. Five of the stock markets record the lowest return on Monday: China, Malaysia, Singapore, Thailand, and Indonesia. Lowest returns also occur on Tuesday for two of the stock markets, namely in the Philippines and in Taiwan.

Table 2: Maximum, minimum and standard deviations of returns, 1998-2003

\begin{tabular}{|c|c|c|c|c|}
\hline 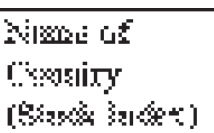 & 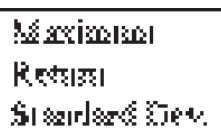 & 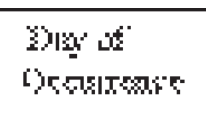 & 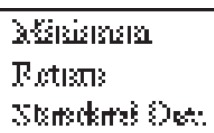 & 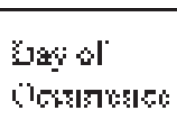 \\
\hline $\begin{array}{l}\text { mines } \\
\text { (\$क्) }\end{array}$ & [1]13 & 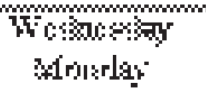 & 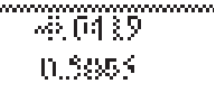 & $\begin{array}{l}\text { Mordey } \\
\text { Porly }\end{array}$ \\
\hline 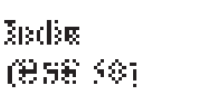 & 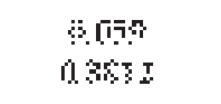 & $\begin{array}{l}\text { Mondi: } \\
\text { Mnerlas: }\end{array}$ & $\begin{array}{l}3102 \\
0.6 \% 13\end{array}$ & 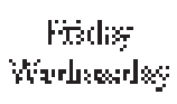 \\
\hline 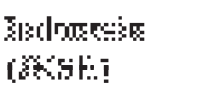 & 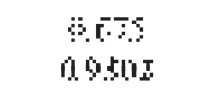 & $\begin{array}{c}\text { |7:ansisy } \\
\text { miकy }\end{array}$ & $\begin{array}{l}805 x \\
0.636 \%\end{array}$ & 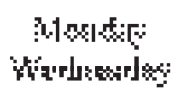 \\
\hline Aikling & 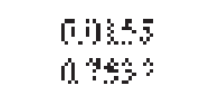 & $\begin{array}{l}\text { 'lmalisy } \\
\text { Arnera: }\end{array}$ & $\begin{array}{c}\sin 5 \\
\sin :\end{array}$ & 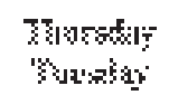 \\
\hline 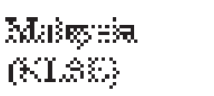 & 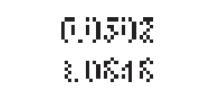 & $\begin{array}{c}\text { Womens } \\
\text { Armerlar }\end{array}$ & $\begin{array}{l}40596 \\
0.6 \% \%\end{array}$ & $\begin{array}{l}\text { Monde } \\
\text { Mankis: }\end{array}$ \\
\hline 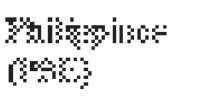 & $\begin{array}{l}0.678 \% \\
0.615 \%\end{array}$ & 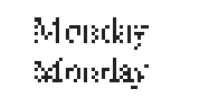 & $\begin{array}{l}300 x \\
x \sin \end{array}$ & 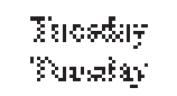 \\
\hline $\begin{array}{l}\text { पimserar } \\
\text { (S) }\end{array}$ & $\begin{array}{l}{[.7455} \\
19004\end{array}$ & $\begin{array}{l}\text { Fimay } \\
\text { armerlay }\end{array}$ & 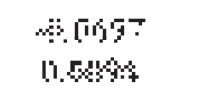 & $\begin{array}{l}\text { Wordex } \\
\text { Wux:alis }\end{array}$ \\
\hline 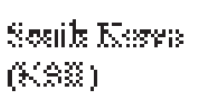 & $\begin{array}{l}813 \\
8.89\end{array}$ & 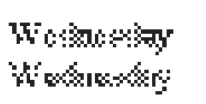 & 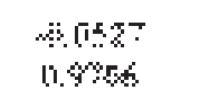 & 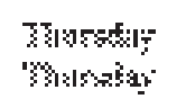 \\
\hline 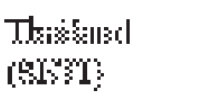 & $\begin{array}{l}0.757 \\
1909 \%\end{array}$ & 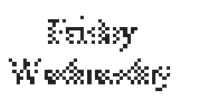 & $\begin{array}{l}\$ 368 \\
10 \% 6\end{array}$ & 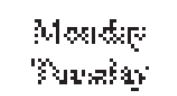 \\
\hline $\begin{array}{l}\text { Trimes } \\
\text { (TWIM }\end{array}$ & $\begin{array}{l}0.6754 \\
03049\end{array}$ & 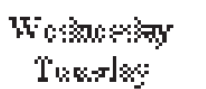 & $\begin{array}{l}4.8196 \\
1.396\end{array}$ & 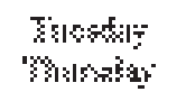 \\
\hline
\end{tabular}


Table 3:Kruskal-Wallis, W-Test for normality and Levene test, 1998-2003

\begin{tabular}{|c|c|c|c|c|c|c|}
\hline \multirow{2}{*}{ 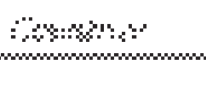 } & \multicolumn{2}{|c|}{$X \% \dot{\alpha} ;$} & \multicolumn{2}{|c|}{ 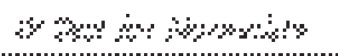 } & \multicolumn{2}{|c|}{ 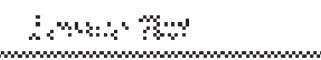 } \\
\hline & 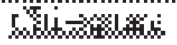 & $28010 \%$ & Stulit $\varnothing$ e & k & $32+101 \%=$ & P) Flatit \\
\hline $\begin{array}{l}\text { mian } \\
\text { mas: }\end{array}$ & $1.4^{T}$ & $\$ .4$ & 3.55 & 6,59 & $.2+43$ & $\sin x$ \\
\hline 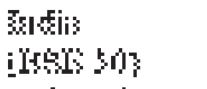 & $\overline{7}$ & $6 x^{2}$ & 281 & 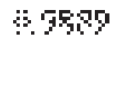 & $4 \ldots 19$ & (6ii]l \\
\hline 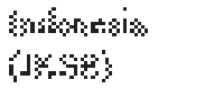 &. .59 & $\$+46+$ & $0 \%$ & 4.4144 & 4.5114 & $66 \%$ \\
\hline 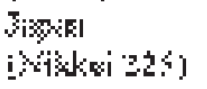 & {$\left[\begin{array}{l}4 \\
07\end{array}\right.$} & 6.5 & $7.4 n]$ & 8595 & 290 & 80.5 \\
\hline 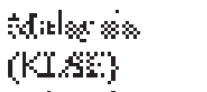 & 164 & $\sin t^{2}$ & 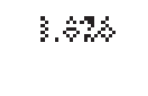 & 0.3514 & 8.18 & 0.5 \\
\hline 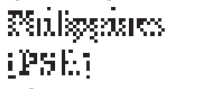 & $51 \%$ & 4.97 & $x \cdot \overline{3}$ & 9.918 & 2712 & 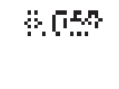 \\
\hline 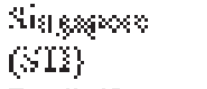 & 7.96 & \$.jpt & $3 \%$ & 0007 & t. & $\theta \sin$ \\
\hline 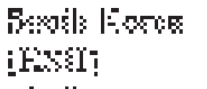 & $8.1 ?$ & 6.84 & $2 \$ 15$ & 8990 & 8.51 & [iiit: \\
\hline 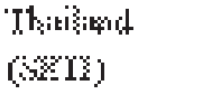 & $2 A$ & $\sin 1)^{+2}$ & $\$ .181$ & \$\$14 & into & 0.17 \\
\hline 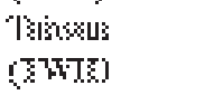 & 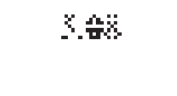 & $\varphi \pm t$ & \pm 64 & क्षेt & $3 \times 4$ & $\dot{4} \geq 41$ \\
\hline
\end{tabular}

This is an interesting finding because in previous studies, the lowest return did not occur on Tuesday for the Philippines and Taiwan. In fact, it is documented that except for New Zealand, Philippines, and Taiwan, all Asia-Pacific stock markets had their lowest return on Tuesday (Ho, 1990: this previous study contained ten Asian Pacific stock markets and excluding Indonesia, China, and India). In this study, Japan and South Korea recorded their lowest returns on Thursday.

China, Malaysia, South Korea, and Taiwan show their highest returns on Wednesday. Highest returns also occurred on Friday for Singapore and Thailand. India and Philippines recorded their highest returns on Monday. Japan and Indonesia recorded their highest return on Tuesday and Thursday, respectively. Even though there is mixed results with respect to which day the highest return occurs, in general, high returns mostly occur on Friday and Wednesday. Previous studies document a highest return on the last trading day of the week (Ho (1990)).

As the skewness and kurtosis statistics of the returns for each day are generally well above zero and 3 respectively, normality of the returns is rejected. This is confirmed by the results of the $W$-test for normality shown below in Table 3. For all the stock markets, the null hypothesis that the sample is normally distributed is rejected, which justifies our use of the no-parametric tests for further analysis.

To substantiate the evidence of the day-of-the-week effects shown in Table 1, the Kruskal-Wallis test is carried out to test the null hypothesis of equality of mean returns across the days of the week. This would correct for the non-nor- 
mality problem invalidating the earlier results. As shown in Table 3, the values of the ${ }^{2}$-statistics are significant at $5 \%$ level for the markets except those in Thailand, Pakistan, and Malaysia.

These results support the existence of the day-of-the-week effect in stock returns in China, India, Japan, Philippines, Singapore, South Korea, and Taiwan. The evidence leads to the conclusion that there is no day-of-the-week effect in Thailand and Malaysia. This result is similar to the previous findings of Wong et al. (1992). Hence, it may be suggested that, although the days on which the effects occur have changed over the recent period after the crisis, day-of-theweek effect is absent for two countries over the pre- and post-crisis period. For others, there is still the day-of-the-week effect significantly present in 8 markets.

\section{B. Volatility of returns}

In general, there seems to be less volatility in the daily returns in these East Asian markets since the Asian Financial crisis. The countries with the highest standard deviation (SD) are those of South Korea (standard deviation of 1.2372), Malaysia (1.0848), and Taiwan (0.8971). These were all emerging economies severely affected by the Asian financial crisis.

Table 1 examined earlier showed the standard deviation of returns. The highest SD of 0.8883 percent is in Taiwan on Tuesday, and the lowest standard deviation of 0.7263 occurs on Thursday. The days on which the maximum and minimum occurs differ from previously reported findings. For example (Ho and Cheung, 1994) documented that the highest standard deviation was for Taiwan occurring on Monday and the lowest occurring on Friday.

In addition, there seems to be a more even distribution across the days of the week regarding the day in which the lowest standard deviations occur. Japan, Philippines, Singapore, and Thailand experience their lowest volatility on Tuesday. Indonesia and India experienced the lowest volatility on Wednesday, while China and South Korea experienced their lowest volatility on Friday.

China, Japan, Malaysia, Philippines, Singapore, South Korea, and India all had the highest volatility on Monday. This evidence is more consistent with past documentation regarding the fact that most of the Asian countries show highest volatility on Monday (see Ho et al. (1994)). Indonesia experienced the highest standard deviation on Friday; Taiwan on Wednesday; and Thailand on Tuesday.

In testing the equality of variance, we used the Levene's test in preference to the more popular Bartlett's test because the non-normality of the distribution had been established for the ten markets included in this study. It has been found that Bartlett's test tends to reject the hypothesis of homoskedasticity more often in the case of non-normal or lepokurtosis distributions. The results of the Levene's test show that in none of the ten countries can the homoskedasticity hypothesis be rejected. We therefore conclude that both the developed and emerging markets 
in the post-crisis period have a low degree of variation across the day-of-theweek returns and this variation is not significant at any level. This observation is at variance with the pre-crisis findings. The earlier findings had indicated that emerging markets have a higher degree of variation in returns across the day-ofthe-week than the developed markets (Ho et al. (1994)). In this study, according to the Levene's statistics, Japan's Nikkei 225 (the most developed market in the test sample) has the highest variation of 3.491. Other emerging markets that ranked high in terms of variation include India's BSE 50, China's SSEC, and Singapore's Strait Times Index with variations of 4.509, 3.451 and 3.893, respectively.

\section{Conclusions}

Not knowing if the reforms and restructuring that occurred during the postAsian financial crisis period has posed a question as to whether the conclusions regarding day-of-the-week effect and volatility patterns in the pre-1998 period still holds, the study on this important issue confirms the existence of the day-ofthe effect week effect in the ten Asian stock markets. The days in which the negative or positive returns or even the minimum and maximum returns had occurred seem to have shifted to other days in some countries. Nevertheless, there is evidence of the day-of-the-week still lingering in the post-crisis period.It has not been traded away. It further confirms that the variation in stock returns is not significant for almost all the Asian countries in this study. However, the results of the Levene's test for homoskedasticity across the days of the week show evidence of lower degree of variation in standard deviation across day-ofthe-week for all the Asian stock markets, which is an important finding. So far, this seems to make sense in that the reforms would be expected to reduce the volatility somewhat. Prior to the Asian financial crisis, the Asian markets were characterized by high returns and volatility. After the crisis, there seems to be a trend toward less volatility and subdued day-of-the-week effect in few of the ten markets tested.

Author statement: Chiaku Chukwuogor-Ndu is a staff of Eastern Connections State University. as the editors are unable to contact Chiaku in time for the production of this issue, we are unable to provide information on research interests. 


\section{References}

Aggarwal, R. and P. Rivoli (1989). Seasonal day-of-the week effects in four emerging stock markets, The Financial Review, 24: 541-50.

Chen, G., Kwok, C.C.Y. and O.M. Rui (2001). The Day-of-the-Week Regularity in the Stock Markets of China. Journal of Multinational Financial Management 11 (2): 139-163.

Condoyanni, L., J. O'Hanion and C. W. R. Ward (1987). Day of the week effect on Stock returns; international evidence, Journal of Business Finance and Accounting 14: 159-74.

Fama, E. F. (1965) The Behavior of Stock Market Prices, Journal of Business, 38: 34-105.

French, K., (1980) Stock returns and the week-end effect, Journal of Financial Economics 8: 55-70.

Gibbons, R.S., and P. Hess (1981). Day of the Week Effects and Asset Returns, Journal of Business 54: 579-96.

Ho, Y. K., 1990, Stock return seasonalities in Asia Pacific markets, Journal of International Financial Management and Accounting, 2, 47-77.

Ho, R. Y. and Y. L. Cheung, 1994, Seasonal pattern in volatility in Asia stock markets, Applied Financial Economics, 4, 61-67.

International Monetary Fund (1999). The IMF's Response to the Asian Crisis, available from $\mathrm{http}: / / \mathrm{www}$.imf.org/external/np/exr/facts/asia.htm\#2.

Jaff, F., Westerfield, R.L., and C. Ma (1989). A twist on the Monday effect in stock prices: Evidence from the U.S. and foreign stock markets, Journal of Banking and Finance 13: 641-50.

Kato, K. (1990). Weekly patterns in Japanese stock returns, Management Science, 36: 1031-43.

Keim, B.D. and and R. F. Stambaugh, 1984, A further investigation of the weekend effect in stock returns, The Journal of Finance, 39, 819-840.

Lakonishok, J., and S. Smidt, 1988, Are seasonal anomalies real? A ninety-year perspective, Review of Financial Studies, 1, 403-25.

Levene, H. (1960) Robust tests for equality of variances in contribution to probability and Statistics, (Ed) 1, Olkin: Stanford University Press, Palo Alto.

Mehdian, S. and M. Perry (2001). The reversal of the Monday effect: new evidence from US equity markets, Journal of Business Finance and Accounting 28: 1043-1066.

Rogalski, R. (1984). New findings regarding day of the week returns over trading and non-trading period, The Journal of Finance 39: 1603-14.

Snedecor, G. W., and W.G. Cochran (1976) Statistical Methods. Ames: Iowa State University Press. 
Smirlock, M., and Starks, L. (1986) Day of the week and intraday effects in stock returns, Journal of Financial Economics 17: 197-210.

Wong, K.A., and H. D. Ho (1986). The weekend effect on stock returns in Singapore, Hong Kong Journal of Business Management 4: 31-50.

Wong, K.A., T.K. Hui and C.Y. Chan (1992). Day-of the week effects: evidence from developing stock markets, Applied Financial Economics 2: 49-56. 